\title{
Clinicopathological and immunohistological profile of infiltrating ductal carcinoma breast in a tertiary care centre of western UP- A study of 100 cases
}

\author{
Mithila Bisht $^{1}$, Shweta Agarwal ${ }^{2, *}$, Ranjan Agrawal ${ }^{3}$ \\ ${ }^{\mathbf{1}}$ Associate Professor, ${ }^{\mathbf{2}}$ Assistant Professor, ${ }^{3}$ Professor, Dept. of Pathology, Rohilkhand Medical College and Hospital, Bareilly, \\ Uttar Pradesh, India \\ *Corresponding Author: Shweta Agarwal \\ Email: drshwetagarwal@gmail.com
}

Received: $7^{\text {th }}$ May, 2018

Accepted: $11^{\text {th }}$ May, 2018

\begin{abstract}
Introduction: Breast cancer is the most common cause of death of women worldwide and it is the most common malignancy in Indian females followed by carcinoma cervix. Diagnosis involves various modalities like clinical examination, radiological investigations, fine needle aspiration cytology (FNAC) and histopathological examination. Recently, immunohistochemistry (IHC), is becoming a standard methodology in pathology laboratories worldwide. IHC provides substantial information with regard to diagnosis, therapeutic prediction and prognosis of breast cancer. Therefore, hormonal studies evaluating the status of estrogen receptor (ER), progesterone receptor (PR) and Human epidermal growth factor-2 (Her2 neu) have become a part and parcel of the histopathology reporting.

Materials and Methods: Present study included 100 cases of Infiltrating Ductal Carcinoma (IDC) breast diagnosed in mastectomy specimens received in department to Pathology, Rohilkhand Medical College and Hospital, Bareilly between July 2014 to June 2017. Other histological variants were excluded from the study. Various parameters including age, site, tumor size, lymph node metastasis, histopathological grading, hormone receptor status namely ER, PR and Her2 neu were studied. The histological grade was correlated with the hormone receptor status.

Results: Majority patients belonged to the age group of 41-50 years (34\%). Most of the carcinomas were of Bloom Richardson grade II (73\%). In terms of the IHC profile, majority were ER/PR negative and Her2 neu positive (45\%).

Conclusion: Breast carcinoma should be studied in all respects in order to understand its behaviour. Additionally, immunohistopathological studies should be carried out in all cases in order to obtain predictive and prognostic information.
\end{abstract}

Keywords: Breast Carcinoma, Grade, Hormone receptor, Bloom Richardson.

\section{Introduction}

In the present era, breast lump, whether benign or malignant, is a source of concern and worry for the patient as well as the treating doctor. Breast cancer is heterogeneous and hormone dependent disease resulting from the mitogenic effects of hormones such as estrogen and progesterone. ${ }^{1}$ In the Indian context, breast cancer is particularly important as it has been recently ranked as the number one cancer among Indian females with age adjusted rate as high as 25.8 per 100,000 women and mortality 12.7 per 100,000 women. ${ }^{2}$ Breast cancer has a heterogeneous prognosis with diverse factors including histologic subtypes, grade, lymph node status, ER, PR, Her2neu status, proliferation activity, status of tumor suppressor genes and oncogenes like BRCA. ${ }^{3}$ Prognosis of breast carcinoma is worse with higher grade, tumor subtypes like medullary and lobular carcinoma, lymph node metastasis, negativity for ER, PR and positivity for Her2neu, with excess of oncogenes and also presence of BRCA-I gene. ${ }^{4}$ Breast cancer projection for India during the time period 2020 suggests the number to go as high as $17,97,900 .^{2}$ Henceforth, evaluation of the possible prognostic parameters such as the hormonal markers and their correlation with grade of tumor is of growing interest. Present study is an attempt to study the prognostic and predictive parameters of carcinoma breast.

\section{Materials and Methods}

The study was approved by the institutional ethical committee. Present study was done on 100 mastectomy specimens received in the department of pathology, Rohilkhand Medical college and Hospital, Bareilly between July 2014 to June 2017. The specimens were grossed as per the standard protocols, subjected to routine tissue processing followed by Haematoxylin and Eosin $(\mathrm{H} \& \mathrm{E})$ staining and IHC staining for ER, PR and Her2 neu. Histopathological features were reported before subjecting the sections for IHC analysis.

Inclusion Criteria: 100 cases of mastectomy specimens having the histomorphological features of Infiltrating Ductal Carcinoma (IDC) breast were included in the study.

Exclusion Criteria: Mastectomy specimens diagnosed as malignant tumors of stromal origin and histological variants other than IDC were excluded from the study. IDC diagnosed on core needle biopsies or lumpectomy specimens was also excluded from the study. 
Histopathological diagnosis based on the morphological features was made by two independent senior pathologists. Lymph node status for metastasis was also assessed. Grading of infiltrating ductal carcinomas was done according to Modified Scarff Bloom Richardson scoring system (Nottingham grading System). Immunohistochemistry panel consisting of estrogen receptor (ER), progesterone receptor (PR) and Her2 neu was applied on the unstained sections in all the cases and results were interpreted. For ER and PR staining Allred scoring system ${ }^{5}$ was applied, which is based on the intensity of staining and proportion of positive tumour cells. Proportion score is given on the basis of percentage of cells showing nuclear stain ( $1 \%$ with score of $1,1-10 \%$ given score of $2,10-33 \%$ given score of 3, 33-66\% given score of 4 and $66-100 \%$ given score of 5 . Intensity score is given as 0 with negative staining, 1 with weak staining, 2 with intermediate staining, and 3 with strong staining. Total score of $>2$ is considered positive for significant expression of ER and PR. For Her2 neu staining, American Society of Clinical Oncology (ASCO) guidelines on the cytoplasmic membrane staining were taken into consideration.

\section{Observation and Results}

Our study included 100 cases of invasive breast carcinoma having histology of infiltrating ductal carcinoma. Age of patients varied from 20-80 years. Maximum number of cases belonged to the age group $41-50(34 \%)$ years followed by $31-40$ years $(32 \%)$. $19 \%$ of the patients belonged to the 51-60 years age group. Least number of cases (2\%) were in 71-80 years age group.

Histological grade of tumor was drawn as per Modified Scarff Bloom Richardson scoring. According to the result, maximum cases were of grade 2 in $73 \%$ of cases followed by 14 cases belonging to grade1 (16\%) and least number of cases i.e.13 belonging to grade $3(13 \%)$.

Other tumor characters are summarized in table 1. Lymph node metastasis was negative in the majority of the cases (63\%). As regards the site for breast carcinoma, right breast (46\%) was slightly more involved than the left breast (43\%). A single case involved bilateral breasts $(1 \%)$. Regarding the size of breast growth, $23 \%$ of cases had size $<2 \mathrm{cms}$ (T1), $52 \%$ measured between 2 to $5(\mathrm{~T} 2) \mathrm{cms}$ and $25 \%$ measured $>5 \mathrm{cms}$ (T3).

In terms of the immunohistochemical findings, it was observed that Her2 neu positivity was seen in maximum number of cases( $80 \%)$. $41 \%$ of the IDC cases were positive for ER and $24 \%$ cases showed PR positivity as depicted in table 2 . This was observed that majority of grade I cases were ER + where as higher grade cases (Grade II \& Grade III) were PR + and HER2 Neu + and this difference was found to be statistically significant. ( $\mathrm{p}$ value $<0.05$ by Fisher's Exact test)

We divided the results of immunohistochemistry results into five broad categories according to their prognostic and predictive values (Table 3) namely, ER+/PR+(with Her2neu negative), ER+PR-, ER-PR+, Her2 Neu+(with ER and PR negative), Triple positive(ER+/PR+/Her2 Neu+) and Triple negative (ER-/ PR-/HER2NEU-). Majority of cases showed the profile of Her2neu +/ER-/PR- (45\%), followed by $\mathrm{ER}+/ \mathrm{PR}-$ in $22 \%$ of the cases. ER-/PR+/Her2 neu- were seen in $11 \%$ of the cases. Almost equal number of cases fell in the category of triple negative $(9 \%)$ and triple positive (8\%). Least number of cases belonged to ER/PR+ category. These results were also correlated with the grade of the tumor, which showed that maximum number of grade II \& grade III tumors were of the immunological profile Her2 neut in $55.71 \%$ and $42.85 \%$ respectively. Grade I tumors showed immunological profile of ER+/PR- in maximum cases $(50 \%)$. It was observed that higher grade cases were having tendency for triple positive/ triple negative/ HER2NEU positive whereas low grade cases had more ER or PR positivity. This difference in distribution was found to be statistically significant. ( $p$ value $<0.05$ by Fisher's Exact test)

\section{Table 1}

\begin{tabular}{|l|c|c|c|}
\hline Tumor Character & Result & No. of cases & Percentage \\
\hline Lymphnode Metastasis & Present & 37 & 37 \\
\cline { 2 - 4 } & Absent & 63 & 63 \\
\hline \multirow{3}{*}{ Side Involved } & Right & 46 & 46 \\
\cline { 2 - 4 } & Left & 43 & 43 \\
\cline { 2 - 4 } & Bilateral & 1 & 1 \\
\hline \multirow{3}{*}{ Tumor Size } & $\leq 2 \mathrm{cms}$ & 23 & 23 \\
\cline { 2 - 4 } & $>2 \mathrm{~cm}$ and $\geq 5 \mathrm{cms}$ & 52 & 52 \\
\cline { 2 - 4 } & $>5 \mathrm{cms}$ & 25 & 25 \\
\hline
\end{tabular}


Table 2

\begin{tabular}{|c|c|c|c|c|c|c|}
\hline & Grade I & Grade II & Grade III & Total & $\begin{array}{c}\text { Percentag } \\
\text { e }(\%)\end{array}$ & $P$ value \\
\hline ER Positive & 15 & 22 & 4 & 41 & 41 & 0.012 \\
\hline PR Positive & 07 & 14 & 3 & 24 & 24 & (Fisher's Exact \\
\hline Her 2 Neu Positive & 08 & 62 & 10 & 80 & 80 & $\begin{array}{c}\text { Test with } \\
\text { simulated p-value) }\end{array}$ \\
\hline
\end{tabular}

Table 3

\begin{tabular}{|c|c|c|c|c|c|c|}
\hline Histological Grade & \multirow{2}{*}{ Grade I } & \multirow{2}{*}{ Grade II } & \multirow{2}{*}{ Grade III } & \multirow{2}{*}{ Total } & \multirow{2}{*}{$\%$} & \multirow{2}{*}{ P Value } \\
\hline Hormone Receptor Status & & & & & & \\
\hline $\mathrm{ER}+/ \mathrm{PR}+$ & 7 & 4 & 0 & 11 & 11 & \multirow{7}{*}{$\begin{array}{c}0.0005 \\
\text { (Fisher's Exact Test } \\
\text { with simulated p-value) }\end{array}$} \\
\hline $\mathrm{ER}+/ \mathrm{PR}-$ & 8 & 13 & 1 & 22 & 22 & \\
\hline ER-/PR+ & 0 & 5 & 0 & 5 & 5 & \\
\hline HER 2 NEU + & 0 & 39 & 6 & 45 & 45 & \\
\hline Triple positive & 0 & 5 & 3 & 8 & 8 & \\
\hline Triple negative & 1 & 4 & 4 & 9 & 9 & \\
\hline Total & 16 & 70 & 14 & 100 & 100 & \\
\hline
\end{tabular}

\section{Discussion}

Breast carcinoma is one of the leading cause of death in women worldwide. It has been ranked the most common cancer in Indian females. ${ }^{2}$ Present study was done on 100 cases of breast carcinoma having the histology of infiltrating ductal carcinoma breast.

The most common age group for IDC breast that was observed in our study was 41-50 years i.e. the perimenopausal and post menopausal age group. The mean age came out to be 48.68 years. These findings are consistent with the studies conducted by other Indian studies like Vedashree et ${ }^{1},{ }^{6}$ Geethamala $\mathrm{K},{ }^{7}$ Chandrika $\mathrm{Rao}^{8}$ and Lakhmini et $\mathrm{al}^{9}$ while it is in contrast with western studies such as study conducted by Rhodes et $\mathrm{al}^{10}$ in which he observed the most common age group for invasive breast carcinomas to be $>50$ years with mean age of 64 years. Usually, in Asian countries breast carcinoma occurs a decade earlier than western countries and also, there is a paradigm shift towards the younger age group. ${ }^{6,11}$ This difference has also been reported in other studies as well and can attributed to the difference in age distribution. In our country only $7 \%$ of the population is above the 60 years age group. ${ }^{7}$ Other factors such as late age of marriage, westernization of diet and reduced breast feeding are also implicated. ${ }^{12}$

In our study, the majority of cases $(52 \%)$ had tumor size between $2-5 \mathrm{cms}$ (T2 stage). This is in coherence with other Indian studies carried out by Biswal et $\mathrm{al}^{4}$ in Cuttack, Vedashree et $\mathrm{al}^{6}$ in Chennai and Suvarchala et $\mathrm{al}^{13}$ in Chennai. Study from a Western country done by Adendaya et al. ${ }^{14}$ showed $71 \%$ cases of breast carcinoma with size less than 2 cms. This can be explained on the basis lack of awareness regarding breast cancer and paucity of breast cancer screening programs in our country and vice versa in the western countries.
In our study right breast was marginally more involved than the left breast, whereas in a study carried out by Geethmala et al, ${ }^{7}$ right breast was involved slightly more than left. This parameter is variable in other studies as well, and is not considered clinically significant.

As regards the Modified Scarff Bloom Richardson grading, in our study, majority of cases belonged to grade II i.e. in $73 \%$ of the total number of cases. This is in coherence with many other Indian studies e.g. studies by Kanchan et al (U.P.), ${ }^{15}$ Vedashree et al (Chennai), ${ }^{6}$ Vasudha et al (Surat), ${ }^{16}$ Suvarchala et al (Chennai) ${ }^{13}$ and Geethamala et al(Bangalore) ${ }^{7}$ where maximum number of tumors belonged to grade II. The histomorphology of all the tumor grades is depicted in Fig. 1.

In our study, lymph node status was positive for metastasis in $37 \%$ of the cases, while it was negative in $63 \%$ of the cases. This is in contrast to the study by Vasudha et $\mathrm{al}^{16}$ where, almost equal number of cases were positive $(53.44 \%)$ and negative $(46.56 \%)$ for metastasis in the axillary lymph nodes.

As regards the stage of the tumors, majority of cases in our study and other Indian studies belonged to stage 2 or 3 , while in western studies, majority cases were detected in stage $1 .^{4,14}$ This can be attributed to the efficient screening and awareness programs for breast carcinoma active in the western world.

In the modern era, no histopathology report of breast carcinoma is considered to be complete without immunohistochemical analysis with respect to ER, PR and Her2 neu. As compared to microarray, immunohistochemistry provides a relatively easier and less expensive modality that can be done on paraffin embedded tissue. These markers have got huge prognostic as well as predictive value. According to the early breast cancer trialists collaborative group, amount of estrogen receptor positivity in the primary tumour 
predicts the benefit the patient will receive from adjuvant endocrine therapy. ${ }^{8}$

Tumors that express both ER and PR have the greatest benefit from hormonal therapy. Normally, HER2/neu receptors control cell growth and repair of healthy breast cells. When Her2 neu is overexpressed, breast cells grow and divide uncontrollably. The tumors expressing Her2 neu are treated using transtuzumab, a humanised monoclonal antibody directed against cells that express HER2 /neu. ${ }^{1}$ Now a days adjuvant therapy in a case of breast carcinoma is determined on the basis of the immunohistochemistry results

As depicted in table 4, ER positivity was seen in $41 \%$ of the cases, PR positivity was present in $24 \%$ of the cases and Her2 neu expression was evident in $80 \%$ of the cases of IDC. This finding is particularly important because of the effectiveness of Trastuzumab (Herceptin) in Her2 neu positive tumors. Therefore, assessment of HER2/neu status in patients with metastatic breast carcinoma has become an even more important clinical consideration. ${ }^{17}$

We compared the immunohistochemical results with other similar studies. In our study majority of cases of breast carcinoma were of the hormonal profile Her2 neu positive/ ER -/PR- seen in $45 \%$ of the cases followed by ER+/PR-(22\% cases) followed by $\mathrm{ER}+\mathrm{PR}+(11 \%$ cases $)$. This is in contrast to many earlier studies carried by Geethmala et al, ${ }^{7}$ Ghosh et al,${ }^{18}$ Ambroise et al, ${ }^{12}$ Suvarchala et al, ${ }^{13}$ Sharif et al, ${ }^{19}$ Adendaya et $\mathrm{al}^{14}$ where majority of cases were of the hormonal profile $\mathrm{ER}+/ \mathrm{PR}+$ but in coherence with a study conducted by Dutta et $\mathrm{al}^{20}$ where Her2 neu positivity of $57.2 \%$ was reported. In various studies conducted in overseas too, Her2 neu positivity was lesser as compared to ER/PR positivity. Amongst the western studies, a study by Priti et $\mathrm{al}^{21}$ in New York, ER positivity was seen in $71.6 \%$ cases, PR was positive in $47.4 \%$ cases and Her2 neu was positive in $47.4 \%$ of cases. In another study conducted in Jordon on 267 cases of breast carcinoma, ER, PR and Her2 neu positivity was $50.8 \%, 57.5 \%$ and $17.5 \%$ respectively. ${ }^{22}$ In a study conducted in Karachi, Pakistan ER,PR and Her2 neu positivity was $32.7 \%, 25.3 \%$ and $24.7 \%$ respectively. The results of present study are not in concordance with the majority of western studies, while the results are more coherence with the studies in the Asian population. This can be attributed to the lower tumor grade and higher age (perimenopausal) at the time of diagnosis. Higher Her2 immunoreactivity may be inherent in breast carcinomas in Indian women. Her2 neu can predict resistance to hormonal therapy. ${ }^{20}$

Other point to be noted was that majority of cases of the hormone profile Her2 neu positive belonged to grade II. This is in contrast to study by Biswal et $\mathrm{al}^{4}$ where Grade 2 tumors showed maximum ER positivity $(40 \%)$ and minimum Her-2/neu positivity and Geethamala et al, ${ }^{7}$ where $64.9 \%$ of grade 2 tumors were $\mathrm{ER}+/ \mathrm{PR}+$. Our study showed very less number of cases (9\%) as triple negative wherein ER, PR and Her2 Neu were negative. Study by Biswal et $\mathrm{al}^{4}$ showed $35 \%$, Bhagat Vasudha $\mathrm{M}$ et al. ${ }^{16}$ showed $25.86 \%$ cases and Patil et al. ${ }^{23}$ showed $19.9 \%$ cases as triple negative respectively. Majority of triple negative cases in our study were of grade III, similar to study conducted by Geethamala $^{7}$ et al. Triple negative tumors carry a poor prognosis, since they are not amenable to hormone therapy. ${ }^{24}$

To summarize the IHC findings, now a days IHC study is advocated as a standard practice all cases of breast carcinoma as it helps in both prognosis (determining the risk of recurrence, mortality) as well as predicting the response to treatment. ${ }^{25}$

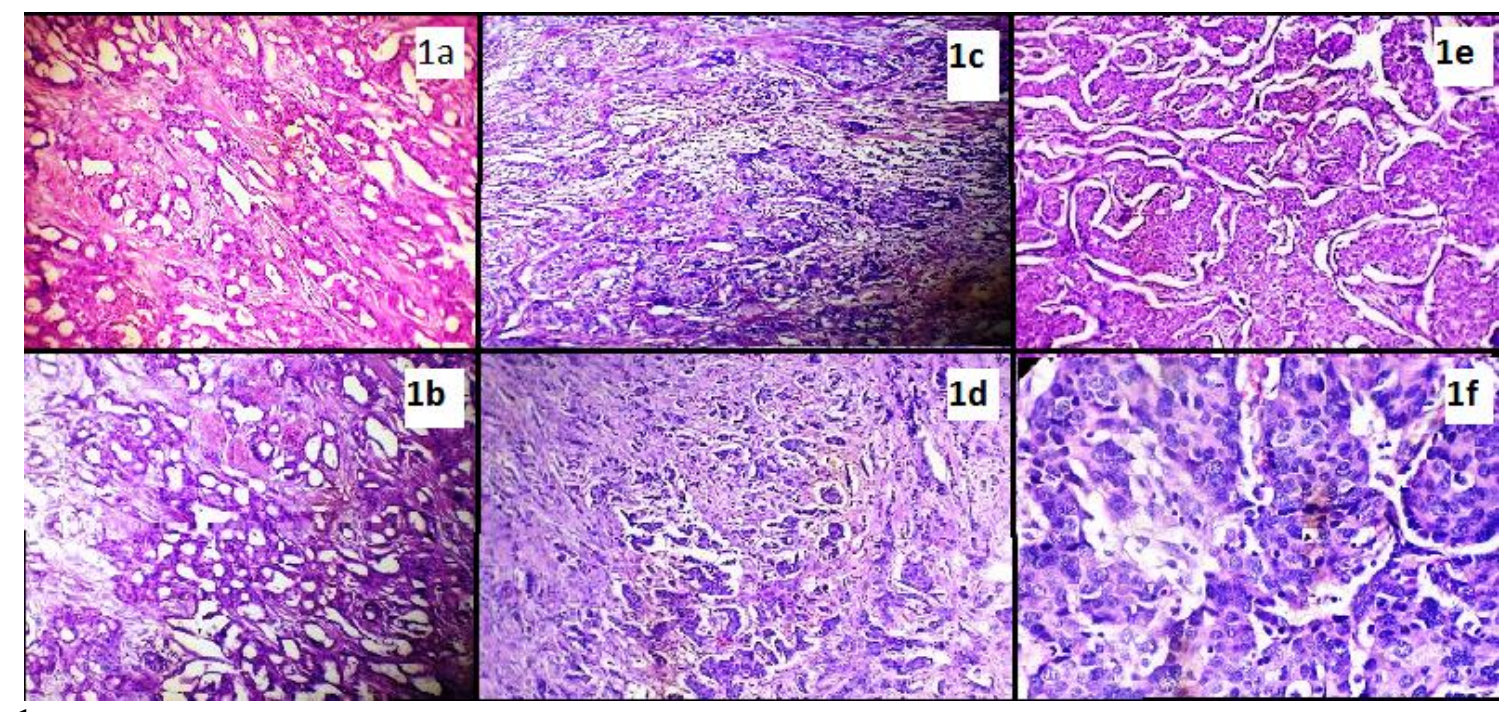

Fig. 1 


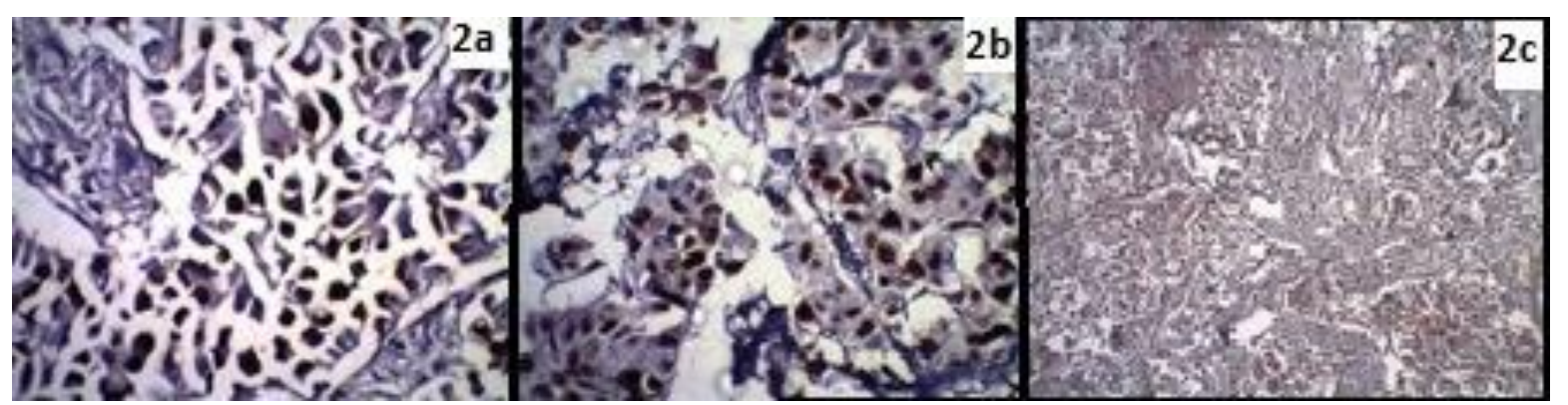

Fig. 2: Positive cases of immunohistochemical staining for ER, PR and Her2 neu

\section{Conclusion}

In our study, Infiltrating Ductal Carcinoma, which is the commonest carcinoma reported worldwide, showed maximum prevalence in 41-50 years age group. ER and PR positivity was seen more in grade I tumors while higher grade tumors were negative for ER/PR. Her2 neu positivity was seen most commonly immunohistochemically and it showed more predilection for higher grades (Grade II \& Grade III). Tumors showing ER and PR positivity carry a good prognosis and respond to hormonal therapy and Her2 neu tumors, though carry a bad prognosis but are particularly responsive to transtuzumab. ER negative and triple negative tumors carry poor prognosis and don't respond to hormonal therapy.

Conflicts of Interest: The authors declare that they have no competing interests.

No financial assistance/grant has been taken.

\section{References}

1. Effi AB, Aman NA, Koui BS, Koffi KD, Traore ZC, Kouyate M. Immunohistochemical determination of estrogen and progesterone receptors in breast cancer: relationship with clinicopathological factors in 302 patients in Ivory Coast. BMC Cancer. 2017;17:115.

2. Malvia S, Bagadi SA, Dubey US, Saxena S.

Epidemiology of breast cancer in Indian women. Asia Pac J Clin Oncol. 2017;13(4):289-95.

3. Naeem, M., Nasir, A., Aman, Z., Ahmad, T. and Samad, A. (2008) Frequency of Her2/Neu Positivity and Its Association with Other Features of Breast Cancer. J Ayub Med Coll, 20, 23-26.

4. Biswal P, Behera S, Kar A, Pradhan D, Behera PK, Burma $S$ et al. Correlation of Hormonal Receptors Estrogen Receptor, Progesterone Receptor and Her-2/Neu with Tumor Characteristics in Breast Carcinoma: Study of 100 Consecutive Cases. International Journal of Clinical Medicine. 2015;6:961-6.

5. Allred DC, Harvey JM, Berardo M, Clark GM. Prognostic and predictive factors in breast cancer by immunohistochemical analysis. Mod Pathol. 1998;11:155-68.

6. Vedashree MK, V. Rajalakshmi. Clinico-pathological study of breast carcinoma with correlation to hormone receptor status \& HER2/neu. Indian Journal of Pathology and Oncology. 2016;3(4);690-5.

7. Geethamala K, Srinivasa Murthy V, Vani BR, Rao S. Histopathological Grade versus Hormone Receptor Status in Breast Carcinoma- Treasure The Past. International Journal of Biomedical Research. 2015;6(07):466-71.
8. Rao C, Shetty J, Prasad K. Morphological profile and recptor status in breast carcinoma: An institutional study. Journal of Cancer Research and Therapeutics. 2013;9(1):44-9.

9. Lakhmini. K.B. Mudduwa. Quick score of hormone receptor status of breast carcinoma: Correlation with other clinicopathological prognostic parameters. Indian Jour of Pathology and Microbiology. 2009;52(2):159-63.

10. Deborah J. Rhodes. Identifying and Counseling Women at Increased Risk for Breast Cancer. Mayo Clin Proc. 2002;77(4):355-61.

11. Meena SP, Hemrajanni DK, Joshi N. A comparative and evaluative study of cytological and histological grading system profile in malignant neoplasm of breast- an important prognostic factor. Indian J Pathol Microbiol. 2005;49(2):199-202.

12. Ambroise M, Ghosh M, Mallikarjuna VS, Kurian A. Immunohistochemical Profile of Breast Cancer Patients at a Tertiary Care Hospital in South India Immunohistochemical Profile of Breast Cancer Patients at a Tertiary Care Hospital in South India. Asian Pacific $J$ Cancer Prev. 2011;12:625-9.

13. Suvarchala SB, Nageswararao R. Carcinoma breasthistopathological and Hormone receptors correlation. $J$ Biosci Tech. 2011;2(4):340-8.

14. Antalio AA, Engel JM, Greenlee RT, Bickol N. Breast Cancer Subtypes Based on ER/PR and Her2 Neu Expression: Comparison of Clinicopathologic Features and Survival. Clin Med Res. 2009;7(2):4-13.

15. Kamini K, Mohan A, Gupta K, Sharma P, Sharma VK. ER/PR status and Apoptotic index in Carcinoma BreastA retrospective study in tertiary teaching hospital in Western UP. IJPO. 2017;4(3):365-7.

16. Bhagat VM, Jha BM, Patel P. Correlation of hormonal receptor and Her-2/neu expression in breast cancer: a study at tertiary care hospital in south Gujarat. Natl J Med Res. 2012;2(3):295-8.

17. Latta EK, Tjan S, Parkes RK, O' Malley FP. The role of HER2/neu overexpression/amplification in the Progression of ductal carcinoma in situ to invasive carcinoma of the breast. Mod Pathol. 2002;15(12):1318 25.

18. Ghosh J, Gupta S, Desai S, Shet T, Radhakrishnan S, Suryavanshi P et al. Estrogen, progesterone and HER2 receptor expression in breast tumors of patients, and their usage of HER2-targeted therapy, in a tertiary care centre in India. Indian J Cancer. 2011;48:391-6.

19. Sharif MA, Mamoon N, Mushtaq S, Khadim, MT, Jamal S. Steroid hormone Receptor Association with Prognostic Markers in Breast Carcinoma in Northern Pakistan. J Coll Physicians Surg Pak. 2010;20:181-5.

20. Dutta V, Chopra GS, Sahai K, Nema SK. Hormone Receptors, Her-2/Neu and chromosomal Aberrations in Breast Cancer. MJAFI. 2008;64:11-5. 
21. Lal P, Tan LK, Chen B. Correlation of Her2 neu status with estrogen and progesterone receptors and histologic features in 3665 invasive breast carcinomas. Am J Clin Pathol. 2005;123:541-6.

22. Sughayer MH, Al-Khwaja M, Massarweh S, Al-Masri M. Prevalence of hormone receptors and Her $2 /$ neu in breast cancer cases in Jordan. Pathol Oncol Res. 2006;12:83-6.

23. Patil VW, Singhai R, Gurav PD. Triple Negative (ER,PR, HER-2/neu) breast cancer in Indian women. Breast Cancer. 2011;3:9-19.

24. Urmila Devi P, Prasad U, Bhagya Lakshmi A, Santa Rao G. A study of correlation of expression of ER, PR and Her2/neu receptor status with clinicopathological parameters in breast carcinomas at a tertiary care centre. Int J Res Med Sci. 2015;3(1):165-73.
25. Shashidhar MR, Shetty PP. Onco-pathological correlation of hormonal receptors and Her2 neu expression in breast cancer. Medpulse International Journal of Pathology. 2017;1(2):23-6.

How to cite this article: Bisht $\mathrm{M}$, Agarwal S, Agrawal R. Clinicopathological and immunohistological profile of infiltrating ductal carcinoma breast in a tertiary care centre of western UP- A study of 100 cases. Indian J Pathol Oncol. 2018;5(4):619-624. 